\title{
NOVOS ATORES EM CENA NA ANTROPOLOGIA
}

\author{
EDIMAR ANTONIO FERNANDES ${ }^{1}$ \\ $U F P A$
}

\begin{abstract}
RESUMO: Nas lutas empreendidas pelos povos indígenas, a descolonização dos "espaços acadêmicos" tem adquirido relevância para os movimentos indígenas e aliados nas últimas décadas. No âmbito da academia, a luta pela descolonização implica na possibilidade do diálogo entre saberes e na valorização da perspectiva do "outro", superando a sobreposição de conhecimentos. Sendo assim, as inúmeras pesquisas, trabalhos e reflexões desenvolvidas por indígenas no âmbito da academia, constituem novas estratégias de enfrentamento. Partindo de minha trajetória de vida e estudantil, pretendo mostrar os caminhos percorridos para alcançar o ensino superior, os desafios e as dificuldades enfrentadas num ambiente hostil, a importância das ações afirmativas e as possibilidades de organização política nestes espaços. Também exponho sobre a experiência de oito anos de trabalho junto aos povos indígenas e populações tradicionais no estado do Pará, fundamentais para formação pessoal, política e acadêmica. Procuro demonstrar como a formação de indígenas em nível superior pode proporcionar o alcance de diálogos entre os diferentes saberes de forma que não se sobreponham, além da vivência da interculturalidade, vencendo resistências e barreiras instituídas em tempos imemoriais.
\end{abstract}

PALAVRAS-CHAVE: descolonização; ensino superior; povos indígenas; ações afirmativas.

ABSTRACT: Amongst the struggles undertaken by indigenous peoples, decolonizing academic spaces has been growing in relevance to indigenous movements and their allies over the past few decades. In the academic sphere, the struggle for decolonization involves exchanging knowledges and valuing the other's perspectives, thus overcoming knowledge overlaps. Therefore, academic work, research and thinking carried out by indigenous individuals inside academia constitute new strategies to face this struggle. Based on the author's personal and academic trajectories, the path followed until achieving higher education, along with its challenges and difficulties, is presented, triggering a discussion about the importance of affirmative actions and the possibilities of political organization in academic settings. This paper points out that indigenous participation in higher education allows intercultural experiences and the exchange of knowledges in a way they don't overshadow one another, overcoming barriers established since time immemorial.

KEYWORDS: decolonization; higher education; indigenous peoples; affirmative action.

\footnotetext{
${ }^{1}$ Kaingang, administrador, mestre em Direito, doutorando junto ao Programa de Pós-Graduação em Antropologia da Universidade Federal do Pará (PPGA/UFPA). Bolsista Capes. E-mail: Kaingang2013@gmail.com.
} 


\section{De coadjuvante ao papel principal}

No percurso das investidas anticolonialistas, muitos povos indígenas lutam contra os efeitos prejudiciais e perturbadores causados pela colonização que se institui adquirindo novos contornos com padrões, práticas e estratégias que desconsideram o outro enquanto um sujeito de conhecimento. No âmbito da academia, a descolonização implica na possibilidade de desconstruir teorias preconceituosas que se estabeleceram historicamente e reproduzem estereótipos para justificar a dominação e subjugação do outro. Partindo deste pressuposto, o ingresso de povos indígenas em cursos de graduação e pós-graduação pode ser entendido como novas estratégias para a mudança de paradigma, momento em que grupos historicamente vulnerabilizados e excluídos tornam-se protagonistas, produzindo conhecimento sobre sua própria realidade. Neste sentido, os debates e as análises suscitadas valorizam a perspectiva dos povos indígenas e pretendem fomentar as discussões acerca do acesso de povos etnicamente diferenciados em instituições públicas de ensino superior, são estratégias de descolonização do conhecimento acadêmico e trazem à cena antropológica novos atores, que saem do papel de informantes para o palco central como protagonistas.

A metodologia adotada para a escrita difere da maioria dos textos, nos quais o autor pouco aparece. Escrevo em primeira pessoa, considerando: (1) a pertença kaingang e (2) a participação nas políticas públicas de acesso de pessoas indígenas ao ensino superior; ou seja, sou indígena pesquisador e usuário das políticas de ação afirmativa na Universidade Federal do Pará (UFPA), marcado pela vivência e participação nas discussões que envolvem as ações afirmativas.

$\mathrm{Na}$ revisão teórica realizada, pude observar que a maioria dos textos que discutem políticas de acesso a instituições de ensino superior voltadas para povos indígenas foram escritos por não indígenas; são pesquisadores envolvidos com as discussões que publicam o resultado dos trabalhos realizados, posicionando-se favoráveis ou não às ações afirmativas. Poucos são os trabalhos escritos 
pelo público protagonista destas políticas, os povos indígenas, o que torna difícil a compreensão da dimensão que as políticas tomam entre os indígenas discentes. A escrita de um trabalho desta envergadura produz inquietações, dúvidas e desconfortos, não apenas de um pesquisador, mas de um kaingang que é protagonista das ações e tem a oportunidade, ainda hoje, de acompanhar o processo de implantação das políticas afirmativas cotidianamente, enquanto escreve.

Considero importante contextualizar que a escolha em pesquisar indígenas no ensino superior toma corpo antes mesmo do meu ingresso no Programa de Pós-Graduação em Antropologia (PPGA), pois a reflexão sobre a minha trajetória de vida e de estudante assume o ponto de partida 2, considerando que, assim como os meus interlocutores, enfrentei inúmeras dificuldades, contando com chances mínimas de sucesso.

\section{Entre a aldeia e a cidade}

Oriundo de família pobre, filho de pai indígena e mãe não indígena, sempre lidei com o trânsito entre a aldeia e a cidade e com conflitos familiares: de um lado, a figura do colonizador representada pela família materna e, de outro, a do colonizado lutando pela retomada do território, formada pela família paterna.

Frequentei o ensino fundamental e médio na rede pública, em escolas indígenas e não indígenas, conciliando a escola com as responsabilidades domésticas e comunitárias, além de exercer alguma atividade remunerada. Mesmo sendo o mais jovem de uma família de quatro filhos, cedo fez-se necessário participar das tarefas da lavoura, capinando, trabalhando no plantio e na colheita para diminuir o peso que recaiu sobre os ombros de minha mãe após o falecimento de meu pai.

A situação crítica enfrentada pela família exigiu que fizéssemos várias mudanças, residindo em casas de parentes maternos em Santa Catarina e no Paraná. As idas e vindas tornaram frequentes as trocas de escola, e cheguei a frequentar cinco escolas diferentes para concluir o

\footnotetext{
${ }^{2}$ A primeira discussão sobre a minha trajetória pode ser encontrada em Fernandes (2010).
} 
ensino fundamental e médio. Sempre ouvi falar sobre a importância da escola, fui instruído, desde cedo, que a "única forma de ser alguém na vida" seria estudando, a afirmativa era justificada pelas poucas alternativas que tínhamos. Não criei muitas expectativas sobre o ensino superior, para mim era algo distante, pouco se ouvia falar sobre o ensino superior no círculo familiar, afinal, não tínhamos parentes formados em nível superior, pensava em concluir o ensino médio e trabalhar. A primeira pessoa da família a ingressar e concluir o ensino superior foi minha irmã mais velha, Rosani de Fatima Fernandes ${ }^{3}$, a qual passou a ser uma referência para mim, visto que foi a pioneira e com frequência relatava suas experiências, mostrando a importância do ingresso na universidade e as diversas possibilidades que a formação poderia proporcionar.

Comecei a pensar com mais seriedade na possibilidade de ingressar no ensino superior em 2001, enquanto concluía o ensino médio na Escola Indígena de Educação Básica Cacique Vanhkre, localizada na Aldeia Sede na Terra Indígena ( $\mathrm{TI})$ Xapecó, município de Ipuaçu (SC). Aquele foi um ano decisivo, as cobranças feitas por Rosani e pelos professores, as conversas com colegas de turma, com as lideranças da aldeia, que demonstravam a necessidade de pessoas formadas para atuar na aldeia, serviram como propulsores para a continuidade dos estudos.

Para os discentes indígenas à época, universidades públicas constituíam-se realidades distantes, as informações sobre estas instituições eram mínimas e, no entendimento da maioria, eram lugares praticamente inacessíveis, sobretudo pela dificuldade relacionada aos processos seletivos e também pela distância das aldeias. Entre os formandos indígenas da minha turma, a Universidade Federal de Santa Catarina (UFSC) era a instituição pública de ensino superior mais conhecida, pouco se ouvia falar da Universidade do Estado de Santa Catarina (UDESC) ou de instituições públicas de outros estados.

No ano que conclui o ensino médio, as Políticas de Ação Afirmativa (PAA) para povos indígenas ainda não eram uma realidade e o acesso de indígenas nos cursos de graduação de universidades públicas ainda não era pauta de discussão em muitas regiões. Neste período, os

\footnotetext{
${ }^{3}$ Para entender melhor a trajetória de Rosani de Fatima Fernandes, consultar Fernandes (2007).
} 
principais debates giravam em torno da criação de Licenciaturas Interculturais ${ }^{4}$.

As alternativas mais acessíveis para nós eram as instituições particulares, as quais ofereciam alguns cursos em municípios próximos das Terras Indígenas. Inicialmente, a Fundação Nacional do Índio (Funai) firmou um acordo com diversas instituições particulares na região, período que assumiu o compromisso de pagar as despesas relacionadas à matrícula e mensalidades dos discentes indígenas. Em decorrência da demanda crescente por acesso a estas instituições por um lado e os cortes orçamentários no órgão indigenista de outro, uma nova política de assistência aos universitários começou a ser discutida e negociada. Sobre o assunto, Maria Helena Fialho, Gustavo Hamilton Menezes e André Ramos (2013) mostram que com o crescimento da demanda e com os cortes orçamentários da Funai, o órgão ficou impossibilitado de atender todos os discentes indígenas.

Para os autores, uma das importantes ações do órgão foi a criação da Coordenação Geral de Educação (CGE), que estabeleceu parcerias e convênios com diversas instituições públicas e particulares. O apoio financeiro pela CGE atendeu estudantes das licenciaturas interculturais e também dos cursos universais, porém com as limitações existentes a maioria dos estudantes indígenas ficam sem qualquer apoio. Como a demanda por apoio é maior que a oferta de recursos, fez-se necessário criar instrumentos jurídicos reguladores. Para tanto, tomou-se como base os critérios contidos na Portaria 63/2006 da Presidência da Funai, que ordena $o$ atendimento aos estudantes pautado em princípios de igualdade de condições para todos os indígenas.

No final de 2001, concorri a uma vaga no curso de Direito da Universidade do Oeste de Santa Catarina (UNOESC) ${ }^{5}$, campus de Xanxerê, mas não obtive êxito no vestibular. Como os processos seletivos geralmente aconteciam no final do segundo semestre, fui obrigado a aguardar por um ano. Durante o período de espera, trabalhei no setor de reflorestamento de uma usina hidrelétrica que estava sendo construída no município, conhecida como UHE Quebra Queixo. Assim

\footnotetext{
${ }^{4}$ As bases teóricas e práticas que garantiram diversas ações voltadas ao ensino superior para povos indígenas no Brasil podem ser consultadas em Souza Lima e Barroso (2013).

${ }^{5}$ A UNOESC integra cinco campi nos municípios de Joaçaba, Videira, Xanxerê, Chapecó e São Miguel do Oeste. Mais informações consultar: http://www.unoesc.edu.br/unoesc/historico.
} 
como eu, muitos outros indígenas trabalhavam na Usina; a grande maioria de nós ocupava cargos que exigiam baixa escolaridade e nenhuma experiência prévia, apenas alguns trabalhavam em outras funções, como motorista, pintor e apontador, por exemplo.

$\mathrm{Na}$ segunda tentativa obtive êxito no vestibular, fui aprovado no curso de Bacharelado em Administração de Empresas na Faculdade Integrada Católica de Palmas (FACIPAL), atualmente, Centro Universitário Católico do Sudoeste do Paraná (UNICS), situada no município de Palmas, no estado do Paraná. Lembro, ainda hoje, da emoção que senti quando soube da notícia da aprovação. Antes mesmo da prova avaliei as dificuldades de estudar em outro estado, e entre morar em Palmas e viajar todos os dias para estudar, escolhi a segunda opção. Sair todos os dias de Santa Catarina para o estado do Paraná demandou esforços significativos, pois precisava viajar por 200 quilômetros da aldeia no percurso de ida e volta; além das despesas com os materiais ainda teria que me preocupar com as despesas relacionadas ao transporte. Durante o primeiro semestre pude contar com o apoio da Funai, que ainda mantinha o acordo com as Instituição de Ensino Superior (IES), e minha matrícula e mensalidades foram pagas integralmente.

Neste período, participei de diversas reuniões que envolveram lideranças da comunidade, indígenas discentes e funcionários da Funai para tratar do apoio aos indígenas que faziam algum curso de nível superior. Até aquele momento, contávamos com o apoio integral para o pagamento das mensalidades. Alegando cortes orçamentários e a impossibilidade de atender a todos os discentes, a Funai diminuiu o apoio para cada estudante. No caso dos que frequentavam a UNOESC, o auxílio era de $100 \%$ nas matrículas e mensalidades - parte garantida pela instituição (50\%) e parte pela Funai (50\%) -; com a mudança, o valor que era pago pela Funai passou a ser dividido com o discente, ou seja, $25 \%$ pago pelo discente e $25 \%$ pela Funai. As reuniões que deveriam ter por objetivo a negociação entre indígenas e o órgão indigenista tiveram como resultado a imposição da Funai e o corte parcial do apoio aos discentes indígenas, mesmo diante das manifestações contrárias.

Quando iniciei o curso em Palmas (PR), fui convidado pelas lideranças da TI Xapecó para lecionar na Escola Indígena de Ensino Fundamental Pinhalzinho como professor de Educação Física, escola 
localizada na aldeia Pinhalzinho na TI Xapecó, no município de Ipuaçu (SC). O período de quase três anos em que atuei como professor foi muito importante para minha formação política e pessoal, pois pude compreender melhor, então como professor, a realidade das escolas indígenas, os problemas enfrentados com a falta de professores capacitados, os problemas com a falta de estrutura e materiais básicos para o funcionamento da escola, além do descaso do Estado com a Educação Escolar Indígena.

No segundo semestre de 2003 consegui a transferência para a UNOESC, campus de Xanxerê, situada a uma distância de $40 \mathrm{~km}$ da aldeia. Com os cortes orçamentários da Funai, passei a pagar $25 \%$ do valor total das mensalidades, o que dificultou ainda mais a continuidade dos estudos. O pequeno salário que recebia trabalhando como professor, com uma carga horária de 30 horas semanais, deixou de ser suficiente por conta das mensalidades; com ele mal conseguia pagar as despesas com transporte, materiais exigidos na Universidade, alimentação e demais despesas. Muitas vezes, fui obrigado a renegociar as dívidas no setor financeiro da Universidade, caso contrário ficaria impossibilitado de fazer a matrícula do semestre seguinte, mas a renegociação acumulava dívidas e a bola de neve sempre aumentava.

\section{Um militante acadêmico...}

Superando as adversidades e as expectativas negativas de alguns colegas e professores, concluí a graduação. Em 2008, por intermédio de Rosani, conheci o edital diferenciado para povos indígenas no Programa de Pós-Graduação em Direito (PPGD) da Universidade Federal do Pará (UFPA), foi a primeira vez que tive contato com instituição pública de ensino superior. Já ouvira falar de ações afirmativas para povos indígenas em universidades no estado do Paraná, também tinha amigos que frequentavam o Curso de Licenciatura Específico para formação de professores indígenas na Universidade do Estado do Mato Grosso (UNEMAT), mas não conhecia nenhuma universidade que oferecesse vagas para indígenas na pós-graduação. $O$ edital oferecia duas vagas específicas para indígenas que se propusessem a trabalhar a temática 
dos Direitos Humanos, atendendo, assim, a grupos que, historicamente, estão em desvantagem.

A partir do curso de pós-graduação em Direito tive a possibilidade de contribuir de forma mais qualificada com as demandas do movimento indígena do estado do Pará. Ingressar via seleção diferenciada para povos indígenas significava muito para mim, foi quando o interesse de entender melhor a discussão sobre as PAA passou a fazer parte da minha vida. A transferência para o estado do Pará para prestar seleção no PPGD exigiu mudanças significativas, a começar pelo deslocamento geográfico e, posteriormente, pelo ritmo de estudo, que diferia do que estava acostumado.

No mestrado tratei da importância do associativismo para os povos indígenas, período em que trabalhei fazendo pesquisas junto ao povo Tembé de Santa Maria do Pará. Cursar as disciplinas possibilitou conhecer mais sobre a construção do Direito no Brasil e os direitos dos povos indígenas ao reconhecimento dos sistemas próprios de Direito vivenciados nas aldeias. Fui brindado com instrumentos que permitem conhecer novos espaços nas discussões acerca da dignidade humana (quilombos, ribeirinhos, extrativistas, enfim, grupos tradicionais historicamente vulnerabilizados), na luta por acesso à educação e saúde de qualidade, habitação, alimentação, enfim, direitos que nos são assegurados como cidadãos brasileiros.

Este período também foi importante para conhecer muitos povos indígenas no estado e estabelecer parcerias, construindo relações de reciprocidade com as lideranças. A minha presença na pós-graduação da UFPA, o acompanhamento das políticas afirmativas que venho realizando desde 2008, a participação como avaliador nos processos seletivos especiais, além da atuação como presidente de uma organização indígena garantiram um espaço de respeito entre os povos indígenas deste estado. Na UFPA, acompanhei e participei das discussões para criação do Processo Seletivo Especial (PSE) para povos indígenas que aconteceram em 2009 e fui um dos idealizadores e fundadores da Associação dos Povos Indígenas Estudantes na Universidade Federal do Pará (APYEUFPA) ${ }^{6}$, instituição que presidi

\footnotetext{
${ }^{6}$ A APYEUFPA foi criada em 2011 e representa os indígenas que estudam no campus da UFPA de Belém. A discussão mais aprofundada sobre a atuação da Associação será realizada no decorrer do texto.
} 
durante três anos consecutivos.

Em face das habilidades como "aprendiz de pesquisador" passei a integrar o Programa de Políticas Afirmativas para Povos Indígenas e Populações Tradicionais (PAPIT), inicialmente como discentecolaborador, auxiliando na formulação e no teste dos instrumentos utilizados em campo. Posteriormente, passei a colaborar com estagiários e bolsistas de iniciação científica, discentes de pósgraduação e docentes do projeto, tornando-me colaborador de atividades e projetos, sempre disposto a aprender no campo do Direito e da Antropologia.

Em decorrência da experiência adquirida com os trabalhos desenvolvidos na APYEUFPA e no PAPIT, enquanto integrante do grupo de pesquisa coordenado pela Prof.$^{a}$ Dr. ${ }^{a}$ Jane Felipe Beltrão, minha orientadora desde o mestrado, pude contribuir com diversas atividades desenvolvidas entre comunidades tradicionais no estado do Pará, dentre as quais, pesquisas desenvolvidas entre os quilombolas no município de Salvaterra, no arquipélago do Marajó; compus uma equipe que realizou palestras e orientações sobre o ingresso no ensino superior e outras temáticas consideradas importantes, como: direito, educação, associativismo, entre outros, para as comunidades quilombolas.

A proposta de orientação e divulgação do PSE para quilombolas, oferecido pela UFPA desde 2012, foi realizado em 2014 e teve como lócus as comunidades de Bacabal, Bairro Alto e Pau Furado. A proposta das "conversas com finalidade" realizadas entre os quilombolas foi sugerida por mim aos integrantes do projeto Indígenas e Quilombolas Mulheres em Situação de Violência: diversidade sociocultural, direitos humanos e políticas públicas na Amazônia (BELTRÃO, 2012), planejada e executada em parceria com colegas de projeto7. Considero a proposta relevante por contribuir significativamente para minha formação, proporcionando a observação das dificuldades enfrentadas por eles no que se refere ao ingresso e permanência no ensino superior e como elas são semelhantes as enfrentadas pelos povos indígenas.

Concluí o mestrado no final de 2013 e logo após fiz a seleção

\footnotetext{
${ }^{7}$ Participaram das atividades desta etapa: Camila Soares de Sousa, Camille Castelo Branco Barata, Cristina Maria Arêda Oshai, Edimar Antônio Fernandes e Rhuan Carlos dos Santos Lopes. Os resultados da etapa de campo compõem o "Relatório da $2^{\mathrm{a}}$ etapa de campo nos quilombos do município de Salvaterra, Marajó (PA).
} 
para o doutorado em Antropologia. Ressalto a importância do ingresso no PPGA da UFPA para a reflexão sobre o fazer antropológico, considero que os textos lidos e as discussões desenvolvidas nas disciplinas, assim como as discussões empreendidas nas formações feitas a partir do grupo de pesquisa Cidade, Aldeia \& Patrimônio, coordenado pela Prof. ${ }^{a}$ Dr. ${ }^{a}$ Jane Felipe Beltrão, foram fundamentais para construção de um pensamento sobre as diversas formas de atuação de junto às comunidades ou povos estudados. O atraente mundo da Antropologia é capaz de envolver de tal maneira, que abre novas possibilidades de ver e entender os contextos de nossas pesquisas e da nossa vida. Limitações existem e as contribuições para o debate teórico da disciplina ainda são restritos, pois, na verdade, estou estreando nesse mundo antropológico, porém acredito que a possibilidade de utilizar o que foi aprendido no trato da pesquisa e nas disciplinas que cursei são significativos para a luta diária que envolve os povos indígenas e a minha atuação enquanto antropólogo e militante.

A formação na área também pode ser considerada como possibilidade de criação de espaços de diálogos entre culturas e realidades específicas, pois, neste espaço, os conhecimentos existentes, os valores individuais e as percepções de mundo estão constantemente sendo colocadas em cheque, sendo questionadas enquanto verdades absolutas, dando espaço ao relativismo e à possibilidade de entender o outro a partir de suas especificidades.

\section{E agora na Antropologia...}

As experiências de vida de antropólogos, colegas indígenas e não indígenas que estão imersos na luta junto aos povos indígenas foram motivação para a escolha da Antropologia. Penso que a Antropologia e os profissionais que atuam na área devem assumir o compromisso de compreender a realidade vivida pelo outro, superando as fronteiras do saber e acessando novas formas de compreender o mundo; ou seja, a Antropologia pode significar um novo entendimento do que os pesquisadores não indígenas discutiram acerca dos povos indígenas no passado, e de como esse entendimento sofreu alterações no decorrer do 
desenvolvimento da disciplina, e das possibilidades de perceber a atuação dos antropólogos e da própria disciplina.

A minha proximidade com a Antropologia a partir da realização de diversas disciplinas, tanto no PPGCS quanto no PPGA, durante a realização do mestrado, assim como o fato de pertencer a um povo indígena e ter tido experiências com antropólogos anteriormente, serviram de lastro para a realização de diversas pesquisas empreendidas durante os oito anos que estou entre os povos indígenas do estado do Pará e, também, para atuar como presidente da APYEUFPA. A atuação enquanto representante de uma organização de estudantes e militante pelos direitos indígenas ultrapassaram os muros da universidade e tiveram respostas razoavelmente positivas até o momento.

Minha presença, na condição de kaingang, na Pós-Graduação em Antropologia parte, principalmente, da necessidade em compreender, numa perspectiva crítica, a realidade social vivida pelos povos indígenas no Brasil. Para entender de forma adequada as nuances do embate fazse imperioso observar os processos históricos que resultaram na situação atual a partir da utilização de instrumentos teóricos e metodológicos disponíveis na Antropologia. Para se elaborar um bom trabalho, é necessário o ir e vir entre a teoria e a prática, conciliando o que foi aprendido no campo teórico, caso de conceitos e categorias estabelecidas na Antropologia, com a prática da pesquisa de campo a partir do "olhar" de um kaingang, possibilitando, assim, uma compreensão ampla da realidade estudada.

Fazer o projeto de tese para ingresso no doutorado, agora em Antropologia, foi tarefa difícil que demandou empenho e dedicação. As preocupações começaram pela definição do campo de pesquisa e do tema a ser abordado, que precede a seleção de ingresso no Programa. Ao refletir sobre a possibilidade de contribuir a partir da discussão aqui empreendida muitas inquietações surgiram: em sendo indígena, como poderia enriquecer a discussão do fazer antropológico? A partir das discussões realizadas, como poderia refletir sobre erros e acertos cometidos no passado e presente, na perspectiva de pensar melhorias? A preocupação em responder tais questões é uma das motivações da escrita do presente texto e as respostas podem não ser fáceis, pois, para um bom desempenho, urge compreender o contexto onde estou 
inserido, o lugar de onde falo e para onde pretendo ir, na perspectiva de proporcionar diálogos igualitários entre os diferentes saberes de forma que não se sobreponham. É a possibilidade de viver a interculturalidade, vencendo resistências e barreiras instituídas em tempos imemoriais.

Para os povos indígenas, a apropriação das pesquisas realizadas na Antropologia se constituem em possibilidade de verificar, contestar ou concordar com o que tem sido escrito, assumindo a responsabilidade de conhecer o que está sendo dito sobre os povos indígenas para elaborar pensamento crítico. Neste sentido, o indígena antropólogo Tonico Benites expressa sua opinião sobre os indígenas formados:

Observo que alguns indígenas já formados e estudantes em Antropologia passam a assumir a função de relator e porta voz de seu povo; tradutores das reivindicações e dos projetos dos povos indígenas que são enviados aos órgãos do Estado e às organizações das sociedades nacionais e internacionais. Além disso, um antropólogo indígena já começa a assumir a função de consultor, perito e tradutor do governo e justiça federal (BENITES, 2015, p. 246).

Conhecer a própria realidade a partir de outras formas de olhar, assim como a realidade que envolve o mundo não indígena, tem sido uma das principais demandas dos povos indígenas. Dominar conhecimentos são estratégias imprescindíveis para a descolonização, assim como para a garantia de que esses direitos se mantenham, afinal, "o Ocidente não pode mais se apresentar como o único provedor de conhecimento antropológico sobre o outro" (CLIFFORD, 1998, p. 19).

A presença de povos indígenas no ensino superior é tema que me causa inquietação desde a graduação. Por ter ingressado em 2003 num curso de graduação fora da aldeia, vivenciei diversas situações que demonstraram o descaso do Estado em relação às políticas de acesso, permanência e sucesso dos povos indígenas nestas instituições de ensino superior (IES). Muitas questões que apresento sobre os indígenas na UFPA já haviam sido observadas em outros contextos e em várias regiões do estado do Pará e do Brasil, também pude acompanhar as lutas de indígenas estudantes em universidades particulares durante minha trajetória acadêmica em Santa Catarina. Portanto, algumas questões aqui problematizadas são fruto de vivência durante a formação 
que não prescinde da compreensão acadêmica.

$\mathrm{Na}$ UFPA, trabalho desde 2010 com os indígenas que ingressam na instituição via ações afirmativas, acompanhei muitas trajetórias acadêmicas e pude contribuir para permanência de muitos parentes na instituição, além de atuar entrevistando pessoas indígenas e quilombolas em cinco Processos Seletivos Especiais. Todavia, as dificuldades enfrentadas pelos parentes na UFPA e os altos índices de desistência observados a partir do acompanhamento feito junto aos indígenas do campus de Belém foram motivo de preocupação. Os dados deste campus nos oferecem uma dimensão de como está a situação dos parentes nos campi da instituição localizados no interior do estado do Pará, razão que motiva obter resposta para perguntas que inquietam: onde estão os indígenas que ingressaram na instituição? Quantos estão estudando? Quantos desistiram? Quantos trancaram a matrícula? Quantos se formaram? Quais as dificuldades enfrentadas por eles? Os indígenas que se formaram, o que estão fazendo? Estão trabalhando nas aldeias? Como estão as comunidades com a saída destes indígenas? Estas são apenas algumas questões das muitas que carecem de resposta.

O tempo na Universidade e a possibilidade de trabalhar em prol dos indígenas estudantes me permitem realizar pesquisa, acompanhar e participar das atividades relacionadas aos povos indígenas na instituição e fora dela. Os trabalhos desenvolvidos compõem relatórios, projetos, entrevistas e outras atividades que, para o movimento indígena, são fundamentais para ajustar o relacionamento com a Universidade. Para um indígena atuante no movimento indígena as atribuições e responsabilidades são contínuas, sendo necessário estar sempre presente, organizando e participando de reuniões, procurando entender as dificuldades enfrentadas pelos indígenas discentes, e como liderança indígena em formação pensar o futuro das ações afirmativas na UFPA é imprescindível.

O percurso acadêmico na UFPA permitiu a ampliação de horizontes e facilitou o conhecimento da realidade de diversos povos indígenas, estabelecendo, assim, relações de parceria com lideranças indígenas no estado do Pará; os trabalhos desenvolvidos e o fato de ser indígena foram minhas credenciais para que os diálogos acontecessem. 
Além disso, a partir do conhecimento adquirido, pude contribuir de maneira crucial para o encaminhamento de diversas demandas de organizações indígenas, lideranças tradicionais e políticas ${ }^{8}$.

Em se tratando de pesquisadores indígenas, é importante lembrar que, apesar dos vínculos de parentesco que possam existir, o que teoricamente contribuiria para o estabelecimento de relações de confiança e reciprocidade não significa que todas as informações serão disponibilizadas pelas lideranças e, mesmo quando disponibilizadas, que elas devam ser divulgadas ao público. As lideranças não têm a obrigação de revelar informações consideradas sigilosas e muito menos de disponibilizar tempo para atender os pesquisadores nos momentos em que forem requeridas, pois possuem responsabilidades, afazeres, e nesse planejamento podemos não estar incluídos, então é sempre importante procurar se adequar aos tempos e espaços cedidos e respeitar, acima de tudo, as decisões internas. Sendo assim, os trabalhos realizados junto aos povos indígenas obedecem dinâmicas próprias, muitas variáveis podem influenciar no andamento das atividades pretendidas. Essas variáveis podem estar relacionadas a: (1) dinâmicas internas, no que se refere às atividades que estão sendo desenvolvidas e (2) aos pesquisadores, no que se refere à forma como se pretende realizar o trabalho.

No âmbito das pesquisas acadêmicas desenvolvidas por indígenas, é responsabilidade do pesquisador identificar e atender aos anseios da comunidade, ajustando os objetivos da pesquisa de acordo com as questões que possam aparecer em campo, onde tudo acontece de forma rápida e exigem muitas vezes habilidade no redirecionamento das ações para que os resultados pretendidos possam ser alcançados em consonância com o que a comunidade espera. Ouvir o outro e falar a partir do que é requerido pelas lideranças e movimentos indígenas é fundamental para o estabelecimento de relações simétricas que resultam em confiança e respeito com povos indígenas. Por fim, para um indígena, trabalhar executando pesquisa acadêmica exige sintonia e

\footnotetext{
${ }^{8}$ Para Luciano (2006), as lideranças indígenas estão organizadas em "lideranças tradicionais" e "lideranças políticas". As lideranças tradicionais são agentes sociais que atuam internamente na manutenção da cultura, organização das atividades e tarefas individuais ou coletivas, entre outras. As lideranças políticas, também chamadas "novas lideranças", são constituídas por pessoas da comunidade que dominam os códigos interétnicos e o conhecimento dos não indígenas.
} 
perspicácia para aproveitar as oportunidades de aprendizado e desenvolver trabalhos que estejam de acordo com as demandas das lideranças e comunidades indígenas; afinal, a descolonização do conhecimento exige que os saberes diversos sejam considerados tão importantes quanto os conhecimentos científicos.

\section{Referências bibliográficas}

BENITES, Tonico. Os antropólogos indígenas: desafios e perspectivas. Novos Debates, Brasília, v. 2, n. 1, p. 244-251, 2015. Disponível em: http://novosdebates.abant.org.br/images/pdf/v2n1.pdf. Acesso em: 13 out. 2015.

CLIFFORD, James. A experiência etnográfica: antropologia e literatura no século XX. Rio de Janeiro: Editora UFRJ, 1998.

FERNANDES, Edimar Antonio. Nas trilhas da (in)visibilidade. Tellus, Campo Grande, v. $10, \quad$ n. $18, \quad$ p. 247-253, 2010. Disponível em: http://www.gpec.ucdb.br/projetos/tellus/index.php/tellus/article/view/209. Acesso em: 15 mar. 2016.

Luta por direitos: estudo sobre a Associação Indígena Tembé de Santa Maria do Pará (AITESAMPA). 2013, 173 f. Dissertação (Mestrado em Direito) - PPGD, UFPA, [2013]. Disponível em: http://repositorio.ufpa.br/jspui/bitstream/2011/6445/1/Dissertacao_LutaDireitosEstudos. pdf. Acesso em: 13 out. 2015.

FERNANDES, Edimar Antonio; BELTRÃO, Jane Felipe; OLIVEIRA, Assis da Costa. Povos Indígenas, Comunidades Quilombolas \& Ensino Superior: a experiência da Universidade Federal do Pará. In: OLIVEIRA, Assis da Costa; BELTRÃO, Jane Felipe (Org.) Etnodesenvolvimento \& Universidade: formação acadêmica para povos indígenas e comunidades tradicionais. Belém: Santa Cruz, 2015. p. 252-280.

FERNANDES, Rosani de Fatima. Pós-Graduação em Direitos Humanos: relato de uma experiência. Tellus, Campo Grande, v. 7, n. 13, p. 149-154, 2007. Disponível em: http://www.tellus.ucdb.br/index.php/tellus/article/view/145/150. Acesso em: 11 out. 2015.

FIALHO, Maria Helena Sousa da Silva; MENEZES, Gustavo Hamilton; RAMOS, André R. F. O ensino superior e os povos indígenas: a contribuição da Funai para constituição de políticas públicas. In: SOUZA LIMA, Antonio Carlos de; BARROSO HOFFMANN, Maria Macedo (Org.). Povos Indígenas e Universidade no Brasil: Contextos e Perspectivas, 2004-2008. Rio de Janeiro: E-papers, 2013. p. 109-118. Disponível em: http://laced.etc.br/site/pdfs/LivroPovosIndigenas.pdf. Acesso em: 20 
jul. 2014.

LUCIANO, Gersem dos Santos. O índio brasileiro: o que você precisa saber sobre os povos indígenas no Brasil hoje. Brasília: MEC/SECAD/LACED/Museu Nacional, 2006. Disponível em: http://www.laced.mn.ufrj.br/trilhas/. Acesso em: 20 jul. 2014.

SOUZA LIMA, Antonio Carlos de; BARROSO, Maria Macedo (Org.). Povos Indígenas e Universidade no Brasil: Contextos e Perspectivas, 2004-2008. Rio de Janeiro: E-papers, 2013. Disponível em: http://laced.etc.br/site/acervo/livros/povosindigenas-e-universidade-no-brasil-contextos-e-perspectivas-2004-2008. Acesso em: 07 jan. 2016.

Recebido em: 16/05/2016 * Aprovado em: 30/05/2016 * Publicado em: 30/06/2016 